\title{
Role of Micro- and Mesosystems in Shaping an Adolescent
}

\author{
Chandrasekaran V' ${ }^{1}$ Kamath VG ${ }^{2}$, Ashok L ${ }^{3}$, Kamath A ${ }^{4}$, Hegde AP ${ }^{5}$, Devaramane V ${ }^{6}$
}

\begin{abstract}
Adolescence is a vulnerable period in an individual's life during which several physiological and psychological changes occur. Increasingly, across the globe, there is increasing incidence of mental health and behavioural problems documented, especially among the youth. The WHO states that mental health conditions and delinquent behaviours contribute significantly to the global disease burden. The transition from adolescence to adulthood is also marked by increasing manifestation of emotional and behavioural disorders with first episodes making their appearance in early adolescence. This review attempts to delve into the influence of microsystem and mesosystems as described by Bronfenbrenner on adolescent behaviours.
\end{abstract}

Key words: Adolescent, Behaviour, Externalizing, Internalizing, Microsystem, Mesosystem

\section{Introduction}

$\Lambda^{d}$ dolescence is a period distinguished by several physiological and psychological changes,often depicted as stress and storm To gain insight into this complex transition, an ecological approach was suggested by Bronfenbrenner in 19941. Across the globe, the immediate family environment as well as cultural norms have continued to change over the years. Bronfenbenner ${ }^{1}$ described that every adolescent is uniquely shaped by the influences in his immediate and external sphere of influence. The 'Microsystem' involves immediate interactions with family, peers, neighbourhood, the school and religious communities. They are often inter-linked with the 'Mesosystem' depicting interactions between the family and school systems. The exo- and macrosystems describe influences that are external to the immediate environment in which the adolescent grows and matures. The World Health Organisation recognises that behavioural problems contribute significantly to the global disease burden ${ }^{2}$. The transition from adolescence to adulthood is also marked by increasing manifestation of emotional and behavioural disorders ${ }^{3}$ with first episodes making their appearance in early adolescence and about $50 \%-70 \%$ extending into adulthood ${ }^{4}$. Across cultures, externalizing deviancy or internalizing problems ${ }^{5}$ amongst adolescents have been well researched to range between $16.5 \%-40.8 \%{ }^{5,6}$ and are on the rise globally ${ }^{7,8,9}$ warranting a closer look. This review attempts to delve into the role of the micro-and mesosystems' influence on shaping adolescent behaviours.
${ }^{1}$ Chandrasekaran, Varalakshmi, Department of Community Medicine, Melaka Manipal Medical College, ${ }^{2}$ Kamath, Veena G., Department of Community Medicine, Kasturba Medical College, ${ }^{3}$ Ashok, Lena.,Prasanna School of Public Health, ${ }^{4}$ Kamath Asha, Department of Biostatistics, ${ }^{5}$ Hegde Asha P, Department of Paediatrics, Melaka Manipal Medical College. All from Manipal Academy of Higher Education, Manipal, India, ${ }^{6}$ Devaramane, Virupaksha, Psychiatrist, AV Baliga Hospital, Udupi, India.

\author{
Address for correspondence \\ Veena G Kamath \\ Department of Community Medicine, \\ Kasturba Medical College, \\ Manipal Academy of Higher Education, \\ Manipal. \\ Tel No; +919845304647 \\ E-mail:veenak@manipal.edu
}

\section{How to cite}

Chandrasekaran V, Kamath VG, Ashok L, Kamath A, Hegde AP, Devaramane V. Role of Micro- and Mesosystems in Shaping an Adolescent. J Nepal Paediatr Soc 2017;37(2):178-183.

doi: http://dx.doi.org/10.3126/jnps.v37i2.18307

This work is licensed under a Creative Commons Attribution 3.0 License. 
Studies included in the review dealt with theoretical insights into parenting practices as well as developmental changes and challenges in a child. Peer reviewed primary research papers in English language, conducted using cross-sectional, longitudinal or intervention designs were selected. Studies were not included if they focused on therapeutic measures or focused on co-morbidities among adolescents that influenced behavioural outcomes. Four literature databases including Pubmed, Embase, PsychINFO and Cochrane Library were searched for literature through December 2016. The key search terms included using parenting style and dimensions, adolescent development, perceptions, and behavioural outcomes.

\section{Discussion}

\section{Family cohesion}

The family is the primary medium where social and cultural norms are instilled in the growing child. Research shows that adolescents who spend quality timeand have more meaningful relationships with their family members tend not to pursue deviance ${ }^{4,10}$. As adolescents grow, family relationships also undergo changes becoming less hierarchical ${ }^{11}$. Consequently, it becomes increasingly important for the family to support the lows and buffer the highs of adolescence. Family cohesion is described at two levels: enmeshment and disengagement. Extremely high levels of cohesion leads to enmeshment, while disengagement is described as too little cohesion, and both are linked with problem behaviors ${ }^{12,13}$. Enmeshed adolescents have been documented to exhibit internalising behaviours while those in disengaged homes showed delinquent behaviors ${ }^{14}$. Age appropriate autonomy along with adequate parental monitoring are emerging as important facets that shape adolescent adaptiveness. A question arises on the bearing the developing adolescent has on parenting. Problem behaviours may have a deleterious effect on the parent-adolescent relationship. Early adolescence is marked by the beginning of 'identity' of self and the need for increasing autonomy. This could drive a wedge between parent-adolescent connectedness, and navigating this phase becomes critical in predicting long-term consequences ${ }^{14}$.

\section{Parenting styles and dimensions:}

Parents as primary caregivers of their offspring exert possibly the greatest impact on the psychological development of a child. They may adopt various styles of parenting, some stemming from their own experiences as children ${ }^{15}$. Baumrind $D^{16}$ identified authoritative, authoritarian and permissive styles while Maccoby and
Marting ${ }^{17}$ included a fourth style known as 'neglectful.' Alternately, the dimensional approach ${ }^{10}$ to parenting assesses different attitudes as well as the nature of the parenting practices. Parenting dimensions have been described in the context of parents expressing 'warmth' or 'control' over their wards.

Authoritative parenting is widely recognised to allow developmental advantages in comparison with those parented in authoritarian, permissive or neglecting households. High levels of parental involvement with effective disciplining and demonstrating higher levels of warmth ${ }^{10}$ are found to be significantly associated with reduction in mental and behavioural problems among adolescents ${ }^{10,18-19}$. Consistent monitoring and supervision are also pertinent aspects of authoritative parenting. Better psychological adjustment was noted among adolescents who were allowed to participate in decision making with their parents across ethnicities ${ }^{4}$. While it is true that adolescents are monitoredto a lesser extent than in childhood, it is important that they feel acknowledged and have the family as a strong buffer $^{20}$. Nevertheless, with increasing age, adolescents acknowledged experiencing higher levels of loneliness, insomnia, anxiety and a sense of hopelessness in various study settings ${ }^{19,21,22}$.

Authoritarian parenting involves highly controlling behaviour and less warmth. Gaps in communication, parental stress, dysfunctional home environments and use of corporal punishment were found to be associated with problem behaviors ${ }^{21,22}$. A breakdown in communication with either parent was associated with anxiety ${ }^{24}$ while unsupportive parenting and use of harsh discipline may precipitate disregard for family norms ${ }^{25}$. Intrusive control by parents with excessive rule setting exerted a negative influence on adolescent psychological expression and were positively correlated with problem behaviors ${ }^{26}$.

Permissive form of parenting includes very warm, passive parents who remain undemanding and indulge their children with freedom. Poor parental monitoring, premature adolescent autonomy, and alternating levels of harsh and lax disciplining known as'seesaw' disciplining have been associated with problem behaviors ${ }^{27,28}$. Unavailable and unsupportive parents may drive adolescents to obtain guidance from possibly deviant alternates.

\section{The sibling effect:}

Sibling relationships provide means of expressing affection and enjoying companionship but can also be marked by conflicts. The occurrence of behavioural problems declined with supportive relationships with 
siblings while conflict and hostility contributed to maladaptive behaviors ${ }^{29}$. Although arguments have existed for and against the heritability in relation to sibling deviance, the role of the family environment has been found to be decisive ${ }^{30}$. Parent-adolescent and adolescent-sibling networks appear to exert significant influence on the psychological adaptation of adolescents. A combination of poor quality parent-adolescent relationship along with siblings who engaged in deviance led to risky behaviors ${ }^{31}$ and influenced suicidal ideation $^{32}$. When the parents and siblings no longer acted as a buffer against the stresses of adolescence, poor behaviours surfaced in the adolescent.

\section{Peers and the developing adolescent:}

Peer groups are important networks wherein the growing adolescent learns the much needed skills for adult life. More recently research suggests that peer influences may shape the development and expression of deviance. Parenting and the family environment mediate the risk factors in relation to self-regulation as well as peer selection ${ }^{33}$. Developmental trajectories have been documented to explain the influence of inefficient parenting, poor childhood behaviours, peer rejection and further into adolescent externalising and internalising behaviors ${ }^{34}$.Inability to regulate impulsive behaviour combined with poor parenting techniques and experiences of rejection may lead to ineffective peer bonding in early childhood ${ }^{35}$. Children then tend toward peers who similarly are rejected which may snowball into less than desirable academic performance and conduct disorders. Deviant peer affiliations formed the bridge between poor parenting practices and adolescent externalising behaviours.

\section{School environment:}

The school environment can wield a lot of influence on the academic as well as social development of adolescents. Researchers emphasize the need for positive school and class-room atmosphere to enhance emotional well-being among adolescents ${ }^{36}$. Parental discord, poor parenting techniques and home environment, particularly among children from economically poor families have been consistently found to co-occur with poor school performance, poor emotional regulation and further onto externalising behaviours. Apart from the proximal influence of the family and home environment, teachers play an important role as a surrogate support system for the adolescent ${ }^{36}$. Adolescents who demonstrate behavioural problems also engage in lifestyles which are inappropriate such as drug addiction or binge drinking which feeds the vicious cycle of poor self-esteem, low social image, poor school performance, bullying and other externalising behaviors ${ }^{37}$.Bully-victims who can play the roles of both bullies and victims were found at greatest risk for suicidal ideation and attempts while also experiencing depression. Research on the more recent phenomenon of school shooting incidents were perpetrated by bully victims who had experienced peer rejection from early years ${ }^{38}$. In combination with lax parental supervision and an unstable familial environment, this can lead to unfavourable outcomes for the adolescent as well to the community.

\section{The demographics of problem behaviour:}

While a large part of literature is dedicated to parenting and the bearing it has on adolescent psychological development, factors such as the family environment including income status and structure of the family have been seen to influence adolescent emotional and behavioural outcomes. Residing in rural areas predicted better mental and behavioural outcomes in comparison with urban adolescents ${ }^{39}$. Reduced connectedness between the parent-adolescent dyad with inadequate family support, low parental education, chronic exposure to poverty and a potentially hazardous home environments increased the adolescent's risks for mental and behavioural disorders ${ }^{40-41}$. Economic stress often figures in relation with unsafe neighbourhoods and higher rates of crime which may lead to poor academic performance or early school drop outs ${ }^{40}$. Poverty can influence the emergence of both externalising and internalising behaviours. High crime neighbourhoods offer accessibility to drugs and alcohol. In the presence of these factors, mediation by unsupportive or violent parenting may predict externalising and anti-social conduct.

Sudden as well as chronic economic strain have been found to be associated with greater conflict between parents and their adolescent children as well as harsher parenting ${ }^{40}$. There is good evidence that living in an intact family is linked with lower risk for problem behaviour onset ${ }^{41}$. The family structure itself has diversified in recent decades. The greatest shifts from the joint family to nuclear have been observed in the Eastern context, particularly in the South Asian region ${ }^{42}$ where traditional family systems are giving way to nuclear structures. Although the structure itself is devolving, this can be described as 'changing' as against 'breaking down.' The unique aspect is that the smaller nuclear units draw their functional and emotional support from the larger family system ${ }^{42,43}$. The increasing need for economic autonomy has been one of the primary reasons for this shift. This phenomenon has been seen in recent decades and its impact on adolescent behavioural outcomes has not 
been sufficiently delved into. Further, the emergence of single parent families poses significant questions on the bearing it has on the children involved. While literature in the western contexts exist, very few emphasize the individual role of the primary parent ${ }^{43}$ and their parenting practices or on the influence that the extended family exerts in the emergence of these behaviours.

Drastic shifts in the family structure, such as divorce, may place the children involved at risk for mental and behavioural problems. In some instances, however, benefits may be observed in that reduction in familial violence or inter-parental conflict influences the adolescents in a positive manner ${ }^{44}$. In families headed by single parents, the psychological balance of the child and consequently the developing youth is influenced by the manner in which the tutelary parent manages the home environment.As the number of non-resident parents grows, adolescent behaviour studied in the context of unbroken intact families may be less representative of processes that affect problem behaviour in this sub-section of youth.

Family structures are also changing in terms of parental gender. Households with same-sex parents raising children have also emerged over the past few decades. The psychological impact on adolescents raised by same-sex parents have been an increasing area of interest in recent years. However, research findings cannot be generalised globally as evidence is not exhaustive. In fact, data from more restrictive societies is lacking. While available evidence has indicated that adolescents in gay households are as well-adjusted as their peers living in heterosexual households, differences of opinion exist ${ }^{45,46}$. Studies indicate that children may experience stigmatising behaviour from peers and the possibility of having gay or lesbian relationships for themselves was considered as an option to a higher degree than adolescents raised in heterosexual homesteads. Authors have, however, emphasised the need of cautiously generalising these findings ${ }^{47}$. Regardless of the type of family, parenting techniques and family cohesion within these families have been found to be significant contributors to the development of the adolescents raised in these families.

In the absence of biological parents, grandparents, the extended family, or foster parents may adopt the role of primary caregivers and the process involved in these contexts are outside the scope of this review.

\section{Concepts in resolution}

The present review sought to gain insight into the influence of relationships within and outside the family context on shaping adolescent behaviours. Each adolescent's psychological makeup is framed by multiple risk and protective factors. In almost every relationship, positive influences promote positive outcomes in adolescents while negative ones pose risks for maladjustment and antisocial behaviours. Childhood familial interactions and behaviours may lay the foundation for future behaviours. Compelling evidence points towards intra-familial processes such as bonding and support systems as well as conflict resolution techniques that mark each relationship within the family, be they inter-parental, parent-adolescent or adolescent-sibling relationships. Parent-adolescent conflict resolution methods may be a much needed skill that helps in learning negotiation skills in adult life. The use of corporal punishment in conflict resolution as a determinant to mental health has also been extensively documented. With age and growing independence from parents, peers become important agencies of support or purveyors of unsociable behaviour. In addition, several references exist to emphasize the role of schools and neighbourhoods. Targeting interventions through the school system in fostering a positive atmosphere among teachers and student peers, along with early identification and redressal of peer victimisation can improve social and psychological maladjustment among at risk adolescents. The changing family structure and composition poses previously unknown influences on the developing adolescent. Further research is warranted as the changing social structures may challenge established findings on adolescent behaviours from intact families headed by heterosexual parents. This again begs further probing within the cultural context as some societies are more accepting than others. The impact of migration on adolescent psychology and behavioural aspects also needs further research as families carry certain traditional values with them which may be challenged in the newer environment. Notwithstanding the influence of myriad factors including intra-familial relationships and peer affiliations, this review concludes that a firm parenting base with adequate and appropriate parentadolescent relationship has a significant bearing on behavioural outcomes in adolescents. The family continues to remain the bedrock for intervention in enhancing behavioural skills among adolescents. 


\section{References}

1. Bronfenbrenner, U. (1994). Ecological models of human development. In International Encyclopedia of Education (Vol. 3, 2nd ed.) Oxford: Elsevier.

2. UNICEF India (India) Adolescence - An age of opportunity [Internet] New Delhi, India [Cited on 2015 June 6] Available at: http://www.unicef.org/india/ media_6785.htm.

3. WHO.int, "WHO Adolescents And Mental Health". N.p., 2016. Web. 26 Feb. 2016.

4. Smetana JG, Campione-Barr N, Metzger A. Adolescent development in interpersonal and societal contexts. Annu Rev Psychol 2006:57:255-84.DOI:10.1146/ annurev.psych.57.102904.190124

5. Pathak R, Sharma RC, Parvan UC, Gupta BP, Ojha RK, Goel NK. Behavioural and emotional problems in school going adolescents. Australas Med J 2011:4(1):15-21.DOI:10.4066/AMJ.2011.464.

6. Malhotra S, Patra BN. Prevalence of child and adolescent psychiatric disorders in India: a systematic review and meta-analysis. Indian $J$ Med Res 2005:122(1):67-79. DOI:10.1186/1753-2000-8-22.

7. Centers of Disease Control and Prevention (CDC) Trends in the prevalence of suicide-related behaviours. [Access on February 26, 2016]; National YRBS: 19912013 from http://www.cdc.gov/healthyyouth/data/yrbs/ pdf/trends/us_suicide_trend_yrbs.pdf.

8. Syed, E., Hussein, S., Haidry, S."Prevalence Of Emotional And Behavioural Problems Among Primary School Children In Karachi, Pakistan - Multi Informant Survey. Indian J Pediatr 2009:76(6):623627. DOI;10.1007/s12098-009-0072-7.

9. Mishra A, Sharma AK. A clinico-social study of psychiatric disorders in 12-18 years school going girls in urban Delhi. Indian J Comm Med 2001:26(2):71-5. DOI:10.1007/s12098-015-1710-x.

10. Chandrasekaran V, Kamath VG, Ashok L, Kamath A, Hegde A, Devaramane V. Parenting dimensions and adolescent perceptions at the root of adolescent behaviours. Asian J Epidemiol 2017:10:150-57. DOI:10.3923/aje.2017.150.157.

11. Steinberg L, Morris AS. Adolescent development. Annu Rev Psychol 2001;52:83-110. DOI:10.1146/ annurev.psych.52.1.83.

12. Jaggers JW. Adolescent Development as a Determinant of Family Cohesion: A Longitudinal Analysis of Adolescents in the Mobile Youth Survey.J Child Fam Stud 2014:24(6):1625-37. DOI:10.1007/ s10826-014-9966-8.

13. Lucia VC, Breslau N. Family cohesion and children's behaviour problems: a longitudinal investigation. Psychiatry Res2006:141(2):141-9 DOI:10.1016/j. psychres.2005.06.009.
14. Moed A, Gershoff ET, Eisenberg N, Hofer C, Losoya S, Spinrad TL, Liew J. Parent-Adolescent Conflict as Sequences of Reciprocal Negative Emotion: Links with Conflict Resolution and Adolescents' Behaviour Problems. J Youth Adolesc 2015:44(8):1607-22. DOI: 10.3923/aje.2017.150.157.

15. Belsky J, Conger R, Capaldi DM. The intergenerational transmission of parenting: introduction to the special section. Dev Psychol 2009:45(5):1201-4.DOI: 10.1037 I a0016245

16. Baumrind, D. Effects of authoritarian parental control on child behaviour. Child Dev1968:37:887-907. DOI:10.2307/1126611.

17. Maccoby E, Martin J. (1983). Socialization in the context of the family: Parent-child interaction. In E.M. Hetherington (Ed.), Handbook of child psychology: Socialization, personality, and social development (Vol. 4, pp. 1-101). New York: Wiley.

18. Hoeve M, Dubas JS, Eichelsheim VI, van der Laan $\mathrm{PH}$, Smeenk W, Gerris JR. The relationship between parenting and delinquency: a meta-analysis. J Abnorm Child Psychol 2009:37(6):749-75. DOI:10.1007/ s10802-009-9310-8.

19. Fosco GM, Stormshak EA, Dishion TJ, Winter CE. Family relationships and parental monitoring during middle school as predictors of early adolescent problem behaviour. J Clin Child AdolescPsychol2012:41(2):202-13.DOI:10.1080/1537 4416.2012.651989.

20. Pegah F. Study of Family Environment and Adolescents' Positive Mental States viz. Happiness, Optimism and Hope: A Cross-Cultural Perspective. AndishehvaRaftar (Applied psychology)2008:3(9):41-8.

21. Malhotra S, Patra BN. Prevalence of child and adolescent psychiatric disorders in India: a systematic review and meta-analysis.Indian $J$ Med Res 2005:122(1):67-79.DOI: 10.1186/1753-2000-8-22.

22. Kim DH, Kim YS, Koh YJ, Leventhal BL. Relationship between behaviour problems and perceived parenting practices in Korean youth. Child Care Health Dev 2013:39(2):194-201. DOI:10.1111/j.13652214.2011.01343.x.

23. Mulvaney MK, Mebert CJ. Stress appraisal and attitudes towards corporal punishment as intervening processes between corporal punishment and subsequent mental health. J Fam Violence 2010;25(4):401-412.DOI: 10.1007/s10896-009-9301-0.

24. Deb, S; Chatterjee, P; Walsh, K. Anxiety among high school students in India: Comparisons across gender, school type, social strata and perceptions of quality time with parents. Australian J Edu Dev Psy2010;10(1);1831.DOI:10.5923/j.ijpbs.20150501.04.

25. Hill NE, Bromell L, Tyson DF, Flint R. Developmental commentary: ecological perspectives on 
parental influences during adolescence. J Clin Child AdolescPsychol 2007:36(3):367-77.DOI: 10.1080/15374410701444322

26. Soenens B, Vansteenkiste M, Smits I, Lowet K, Goossens L. The Role of Intrusive Parenting in the Relationship between Peer Management Strategies and Peer Affiliation. J Appl Dev Psychol2007:28(3):239-49. DOI: 10.1016/j.appdev.2007.02.003

27. Bae, D \& KAS Wickrama. Family Socioeconomic Status and Academic Achievement Among Korean Adolescents: Linking Mechanisms Of Family Processes and Adolescents' Time Use. J Early Adolesc 2014:35(7):1014-38.DOI: 10.1177/0272431614549627

28. Fröjd, S, Kaltiala-Heino R, Rimpelä M. The Association Of Parental Monitoring And Family Structure With Diverse Maladjustment Outcomes In Middle Adolescent Boys And Girls. Nord J Psychiatry2007:61(4):296-303. DOI:10.1080/08039480701415277

29. Soli, Anna R., Susan M. McHale, and Mark E. Feinberg. Risk and Protective Effects Of Sibling Relationships Among African American Adolescents. Fam Rel 2009:58(5):578-92. DOI: 10.1111/j.17413729.2009.00576.x

30. Yuan, ASV. Sibling relationships and adolescents' mental health the interrelationship of structure and quality. J Fam Issues 2009:30(9):1221-44. DOI:10.1177/0192513X09334906

31. Bullock BM, Dishion TJ. Sibling collusion and problem behaviour in early adolescence: Toward a process model for family mutuality. J Abnorm Child Psychol 2002:30(2):143-53. DOI:10.1023/A:1014753232153

32. Low S, Shortt JW, Snyder J. Sibling Influences on Adolescent Substance Use: The Role of Modeling, Collusion, and Conflict. Dev Psychopathol 2012:24(01):287-300.DOI: 10.1017/ S0954579411000836

33. Mrug S,Windle M. Moderators of Negative Peer Influence on Early Adolescent Externalising Behaviours: Individual Behaviour, Parenting, and School Connectedness. J Early Adolesc 2008:29(4):518-40. DOI: 10.1177/0272431608324473

34. Wang MT, Dishion, TJ. The Trajectories of Adolescents' Perceptions of School Climate, Deviant Peer Affiliation, and Behavioural Problems during the Middle School Years. J Res Adolesc 2012:22(1):40-53. DOI:10.1111 \%2Fj.1532-7795.2011.00763

35. Prinstein MJ \& La Greca AM. Childhood Peer Rejection and Aggression As Predictors of Adolescent Girls' Externalising And Health Risk Behaviours: A 6-Year Longitudinal Study. J Consult ClinPsychol2004:72(1):103-12. DOI:10.1037/0022006X.72.1.103
36. O'Connor EE, Dearing E, \& Collins, BA. Teacher-child relationship and behaviour problem trajectories in elementary school. Am Educ Res J2011:48(1):120-62. DOI:10.3102/0002831210365008

37. Laukkanen E, Shemeikka S, Notkola IL, KoivumaaHonkanen $\mathrm{H}, \quad$ NissinenA. Externalising and internalising problems at school as signs of healthdamaging behaviour and incipient marginalization. Health PromotInt 2002:17(2):139-46. DOI:10.1093/ heapro/17.2.139

38. Hong JS, Cho H, Allen-Meares $\mathrm{P}$, and Espelage, DL. The social ecology of the Columbine High School shootings. Child Youth Serv Rev2011:33(6):861-68. DOI:10.1016/j.childyouth.2010.12.005

39. Tick NT, van der Ende J, Verhulst FC. Ten-year trends in self-reported emotional and behavioural problems of Dutch adolescents. Soc Psychiatry PsychiatrEpidemiol 2008;43(5):349-55. DOI:10.1007/s00127-008-0315-3

40. Pillai A, Patel V, Cardozo P, Goodman R, Weiss H, Andrew G. Non-traditional lifestyles and prevalence of mental disorders in adolescents in Goa, India. Br J Psy 2008:192(1):45-51. DOI:10.1192/bjp.bp.106.034223

41. PlybonLE,Kliewer W. Neighborhood types and externalising behaviour in urban school-age children: Tests of direct, mediated, and moderated effects. JChildFam Studies 2001:10(4):419-437. DOI:10.1023/A:1016781611114

42. Bahadur A,Dhawan N. Social value of parents and children in joint and nuclear families. Journal of the Indian Academy of Applied Psychology 2008:34:74-80

43. Mak KK, Ho SY, Thomas GN, Schooling CM, McGhee SM, Lam TH. Family structure, parent-child conversation time and substance use among Chinese adolescents. BMC Public Health 2010:10:503. DOI:10.1186/1471-2458-10-503

44. Singh A, Kiran UV. Effect of single parent family on child delinquency. IntJ Sci Re 3 (9):866-868.

45. Van Gelderen L, Bos HM, Gartrell N, Hermanns J, Perrin EC. Quality of life of adolescents raised from birth by lesbian mothers: the US National Longitudinal Family Study. J Dev BehavPediatr2012:33(1):17-23. DOI:10.1097/DBP.0b013e31823b62af

46. Short E, Riggs DW, Perlesz A, Brown R, Kane G, 'Lesbian, Gay, Bisexual and Transgender (LGBT) Parented Families: a literature review prepared for The Australian Psychological Society, Melbourne: Australian Psychological Society 2007:29 [Cited on 2015 June 6] Available at: http://www.psychology.org. au/Assets/Files/LGBT-Families-Lit-Review.pdf

47. Wainright J \& Patterson C. Peer relations among adolescents with female same-sex parents. Dev Psychol 2008:44(1):117-126.DOI: 10.1037/00121649.44.1.117. 